\title{
Angiotensin 1-7 ameliorates caerulein-induced inflammation in pancreatic acinar cells by downregulating Toll-like receptor 4/nuclear factor- $\kappa B$ expression
}

\author{
YAN WANG $^{1}$, GUOXING WANG ${ }^{1}$, LIJIAN CUI ${ }^{2}$, RUIXIA LIU ${ }^{3}$, HONGLI XIAO ${ }^{1}$ and CHENGHONG YIN ${ }^{3}$ \\ ${ }^{1}$ Department of Emergency, Beijing Friendship Hospital, Beijing 100050; ${ }^{2}$ Department of Emergency, \\ Beijing Chao-Yang Hospital, Beijing 100020; ${ }^{3}$ Department of Internal Medicine, \\ Beijing Obstetrics and Gynecology Hospital, Capital Medical University, Beijing 100026, P.R. China
}

Received March 22, 2017; Accepted September 11, 2017

DOI: $10.3892 / \mathrm{mmr} .2017 .8354$

\begin{abstract}
The present study aimed to investigate the effects of angiotensin (Ang) 1-7 on caerulein (CAE)-stimulated nuclear factor $(\mathrm{NF})-\kappa \mathrm{B}$, Toll-like receptor (TLR4) and cytokine expression using pancreatic acinar AR42J cells. AR42J cells were treated with $10 \mathrm{nmol} / \mathrm{l} \mathrm{CAE}$ for various durations. In addition, cells were pretreated with various concentrations of Ang 1-7 or A779, a specific antagonist of Ang 1-7, and were stimulated with CAE for $12 \mathrm{~h}$. Control cells were treated with vehicle (F-12K complete medium with $2 \%$ fetal bovine serum, $10 \mathrm{U} / \mathrm{ml}$ penicillin and $100 \mathrm{mg} / \mathrm{ml}$ streptomycin) alone. The mRNA and protein expression levels of TLR4, NF- $\kappa$ B, interleukin (IL)-6, IL-8, IL-10 and tumor necrosis factor- $\alpha$ (TNF- $\alpha$ ) were determined by western blotting, immunofluorescence and reverse transcription-quantitative polymerase chain reaction. CAE treatment stimulated TLR4 and $\mathrm{NF}-\kappa \mathrm{B}$ expression within AR42J cells. Immunofluorescence indicated that TLR4 was expressed on the membranes and in the cytoplasm of AR42J cells, whereas NF- $\mathrm{BB}$ expression accumulated in the cytoplasm and nuclei. CAE-induced expression of TLR4 and NF- $\kappa$ B within AR42J cells was abrogated by $10^{-5} \mathrm{mmol} / 1$ Ang 1-7; however, TLR4 and NF- $\kappa \mathrm{B}$ expression was enhanced with the addition of A779, particularly $10^{-5} \mathrm{mmol} / \mathrm{l}$. In addition, treatment with $10^{-6}$ and $10^{-5} \mathrm{mmol} / \mathrm{l}$ Ang 1-7 significantly mitigated CAE-induced expression of IL-6, IL- 8 and TNF- $\alpha$,
\end{abstract}

Correspondence to: $\mathrm{Dr}$ Chenghong Yin, Department of Internal Medicine, Beijing Obstetrics and Gynecology Hospital, Capital Medical University, 251 Yaojiayuan Road, Chaoyang, Beijing 100026, P.R. China

E-mail: modscn@126.com

Abbreviations: Ang, angiotensin; CAE, caerulein; RAS, renin-angiotensin system; ACE2, angiotensin I converting enzyme 2; AP, acute pancreatitis; TLRs, Toll-like receptors; LPS, lipopolysaccharide; TNF- $\alpha$, tumor necrosis factor- $\alpha$

Key words: AR42J cells, angiotensin 1-7, Toll-like receptors 4, nuclear factor- $\mathrm{\kappa B}$, inflammatory cytokines whereas it enhanced IL-10 expression. Conversely, A779 treatment enhanced the CAE-induced expression of IL-6, IL-8 and TNF- $\alpha$, and reduced IL-10 expression in AR42J cells. In conclusion, these results suggested that Ang 1-7 may attenuate CAE-induced inflammation by downregulating TLR4, NF- $\kappa \mathrm{B}$ and proinflammatory cytokine expression within AR42J cells. Therefore, Ang 1-7 may exert protective effects against the pathological progression of AP in a cell model of AP induced by CAE and may be considered in the development of treatments for this disease.

\section{Introduction}

The renin-angiotensin system (RAS) has been implicated in the pathophysiology of pancreatitis (1). Evidently, high levels of angiotensin I converting enzyme 2 (ACE2), angiotensin (Ang) 1-7, and its corresponding receptor Mas, expression are detected in plasma and in the pancreas of mice with acute pancreatitis (AP). These factors serve protective roles during the pathogenesis of pancreatitis within mice (2). Ang 1-7 has been reported to serve as an endogenous antagonist of Ang II, possessing anti-inflammatory and vasodilatory activities, and exerting protective effects against endothelial injury (3-5). Our previous study revealed that caerulein (CAE) can stimulate the ACE2-Ang-1-7-Mas axis and significantly inhibit pancreatitis development via endothelial nitric oxide synthase activation and nitric oxide signaling within AR42J cells (6). In addition, further study identified that in the AR42J cells stimulated by CAE, blocking of Mas receptor using A779, then enhancement of Ang (1-7), still can reduce the inflammatory response. It is therefore hypothesized that Ang (1-7) has other anti-inflammatory pathways besides the Mas receptor pathway; however, further investigation is required.

Toll-like receptors (TLRs) are required for the onset of inflammation, and can initiate inflammatory signaling (7). TLR4 is a member of the TLR family and is expressed by pancreatic macrophages, acinar cells and stellate cells (8). Engagement of TLR4 with its ligands, such as lipopolysaccharide, can activate the nuclear factor (NF)- $\kappa \mathrm{B}$ signaling pathway and induce the expression of tumor necrosis factor- $\alpha$ $(\mathrm{TNF}-\alpha)$, and other proinflammatory cytokines that lead to 
pancreatic inflammation (9-12). During the pathogenesis of $\mathrm{AP}$, the RAS also regulates the $\mathrm{NF}-\kappa \mathrm{B}$ signaling pathway and cytokine production, which contributes to the pathogenesis of AP (13). Our previous study reported the expression of Ang 1-7 within AR42J cells; high levels of circulating Ang 1-7 were detected within mice with severe AP (SAP) (2). However, it is unclear whether endogenous and exogenous Ang 1-7 can regulate TLR4 and NF- $\kappa \mathrm{B}$ expression within AR42J cells during the inflammatory process. In the present study, a cellular model was employed to investigate the effect of Ang 1-7 on the expression of TLR $4, N F-\kappa B$ and inflammatory cytokines within AR42J cells.

\section{Materials and methods}

Cell culture and grouping. Rat pancreatic acinar AR42J cells [American Type Culture Collection (ATCC), Manassas, VA, USA] were cultured in F-12K medium (ATCC) containing $20 \%$ fetal bovine serum (Gibco; Thermo Fisher Scientific, Inc., Waltham, MA, USA), $100 \mathrm{U} / \mathrm{ml}$ penicillin and $100 \mu \mathrm{g} / \mathrm{ml}$ streptomycin (complete medium) at $37^{\circ} \mathrm{C}$ in a humidified atmosphere containing $5 \% \mathrm{CO}_{2}$. Cells were stimulated with $10 \mathrm{nmol} / \mathrm{l} \mathrm{CAE}$ (Sigma-Aldrich; Merck KGaA, Darmstadt, Germany) for 0.25, $0.5,2,6,12$ or $24 \mathrm{~h}$ to induce inflammation (14). All drug intervention group cells were stimulated at room temperature, and then incubated at $37^{\circ} \mathrm{C}$ in a humidified atmosphere containing $5 \% \mathrm{CO}_{2}$. In addition, cells were treated with vehicle $[\mathrm{F}-12 \mathrm{~K}$ medium containing $5 \%$ fetal bovine serum (Gibco; Thermo Fisher Scientific, Inc.)] alone (Control) or $10 \mathrm{nmol} / \mathrm{l} \mathrm{CAE}$ for $12 \mathrm{~h}$ (Model). Some cells were pretreated with Ang 1-7 (10 ${ }^{-7}$, $10^{-6}$ or $10^{-5} \mathrm{~mol} / \mathrm{l}$; Sigma-Aldrich; Merck KGaA) or Ang 1-7 antagonist A779 $\left(10^{-7}, 10^{-6}\right.$ or $10^{-5} \mathrm{~mol} / \mathrm{l}$; Sigma-Aldrich; Merck $\mathrm{KGaA}$ ) for $12 \mathrm{~h}$ and stimulated with $10 \mathrm{nmol} / \mathrm{l} \mathrm{CAE}$ for $12 \mathrm{~h}$. The groups of differentially treated cells were harvested for subsequent experimentation.

Immunofluorescence assay. Expression levels of TLR4 and $\mathrm{NF}-\kappa \mathrm{B}$ in the control and model cell groups were determined by immunofluorescence analysis. Briefly, cells of the control and model groups were harvested and washed in phosphate-buffered saline ( $\mathrm{pH} 7.4)$, fixed in $4 \%$ (v/v) paraformaldehyde at $37^{\circ} \mathrm{C}$ for $40 \mathrm{~min}$, and were then treated with $1 \%$ bovine serum albumin (Gibco; Thermo Fisher Scientific, Inc.) at $37^{\circ} \mathrm{C}$ for $30 \mathrm{~min}$. The cells were incubated with rabbit anti-TLR4 (ab22048; 1:200; Abcam, Cambridge, UK) and anti-NF-кB p65 (8242; 1:200; Cell Signaling Technology, Inc., Danvers, MA, USA) or control rabbit immunoglobulin G (IgG; ab6730; 1:200; Abcam, Cambridge, UK) at $4^{\circ} \mathrm{C}$ overnight. Cells were washed and incubated with fluorescein isothiocyanate-conjugated goat anti-rabbit IgG (bs-0295M-FITC; 1:100; BIOSS, Beijing, China) for $40 \mathrm{~min}$ at $37^{\circ} \mathrm{C}$ followed by staining with DAPI (Santa Cruz Biotechnology, Inc., Dallas, TX, USA). The cells were examined under a fluorescent microscope and images were captured.

Western blotting. Harvested cells were lysed using lysis buffer (BIOSS, Beijing, China) and were centrifuged $(25,155 \mathrm{x} \mathrm{g}$ for $15 \mathrm{~min}$ at $4^{\circ} \mathrm{C}$ ). Following quantification of protein concentrations using a Bicinchoninic Acid Protein Assay kit (Pierce; Thermo Fisher Scientific, Inc., Waltham, MA, USA), cell lysate proteins $(25 \mu \mathrm{g} /$ lane $)$ were separated by $10 \%$ SDS-PAGE and were transferred onto polyvinylidene fluoride membranes. The membranes were incubated with $5 \%$ non-fat dry milk in Tris-buffered saline containing $2 \%$ Tween at $37^{\circ} \mathrm{C}$ for $2 \mathrm{~h}$ and were then incubated with monoclonal rabbit anti-mouse TLR4 (ab22048; 1:800; Abcam), anti- $\beta$-actin (4970; 1:500; Cell Signaling Technology, Inc.), or anti-NF-кBp65 (8242; 1:800; Cell Signaling Technology, Inc.) at $4^{\circ} \mathrm{C}$ overnight. Membranes were washed and were incubated with peroxidase-conjugated goat anti-rabbit antibodies (sc-2004; 1:5,000; Santa Cruz Biotechnology, Inc.) for $1 \mathrm{~h}$ at $25^{\circ} \mathrm{C}$ and were visualized using enhanced chemiluminescence detection reagents (EMD Millipore, Billerica, MA, USA). The relative levels of target protein compared with $\beta$-actin were determined via densitometric analysis using Image software version 3.0 (Bio-Rad Laboratories, Inc., Hercules, CA, USA).

\section{Reverse transcription-quantitative polymerase chain reaction} (RT-qPCR). Total RNA was extracted from different groups of cells using TRIzol reagent (Invitrogen; Thermo Fisher Scientific, Inc.,) and reverse transcribed into cDNA using the High Capacity cDNA Reverse Transcription kit (Fermentas; Thermo Fisher Scientific, Inc., Pittsburgh, PA, USA) according to the manufacturer's protocol. The resultant cDNA served as templates for RT-qPCR using the Power SYBR Green PCR Master Mix (Applied Biosystems; Thermo Fisher Scientific, Inc.) and specific primers in an Applied Biosystems 7500 fast platform (Applied Biosystems; Thermo Fisher Scientific, Inc.). The primer sequences were: IL-6 forward, 5'TGCCTT CTTGGGACTGAT3' and reverse, 5'CTGGCTTTGTCTTTC TTGTTAT3' (384 bp); IL-10 forward, 5'CCTGGTAGAAGT GATGCC3' and reverse, 5'CACCTTTGTCTTGGAGCT3 (191 bp); IL-8 forward, 5'TCGTCCACGCCACAAGTA3' and reverse, 5'CAGTAGTCCGAAGAATGAAG3' (117 bp); TNF- $\alpha$ forward, 5'CCACGCTCTTCTGTCTACTG3' and reverse, 5'GCTACGGGCTTGTCACTC3' (145 bp); and GAPDH forward, 5'CTCAACTACATGGTCTACATGTTCCA-3' and reverse, 5'-CTTCCCATTCTCAGCCTTGACT-3' (81 bp). The qPCR reactions were performed in triplicate at $95^{\circ} \mathrm{C}$ for $10 \mathrm{~min}, 95^{\circ} \mathrm{C}$ for $15 \mathrm{sec}$, and $60^{\circ} \mathrm{C}$ for $1 \mathrm{~min}$ for 40 cycles. Data were normalized to GAPDH and analyzed by the $2^{-\Delta \Delta \mathrm{Cq}}$ method (15).

Statistical analysis. All cell experiments were repeated three times, and all data are expressed as the mean \pm standard deviation. The difference among groups was determined by one-way analysis of variance followed by a Newman-Keuls test using the Statistical Package for Social Sciences software for Windows, version 16.0 (SPSS, Inc., Chicago, IL, USA). $\mathrm{P}<0.05$ was considered to indicate a statistically significant difference.

\section{Results}

CAE enhances TLR4 and NF- $\kappa B$ expression in AR42J cells. In order to investigate the effects of CAE on TLR4 and NF- $\kappa \mathrm{B}$, AR42J cells were treated with or without $10 \mathrm{nmol} / \mathrm{l} \mathrm{CAE}$ for various durations; TLR4 and $N F-\kappa B$ expression within AR42J cells was determined by western blotting (Fig. 1A). Compared with the control group, treatment with CAE for 

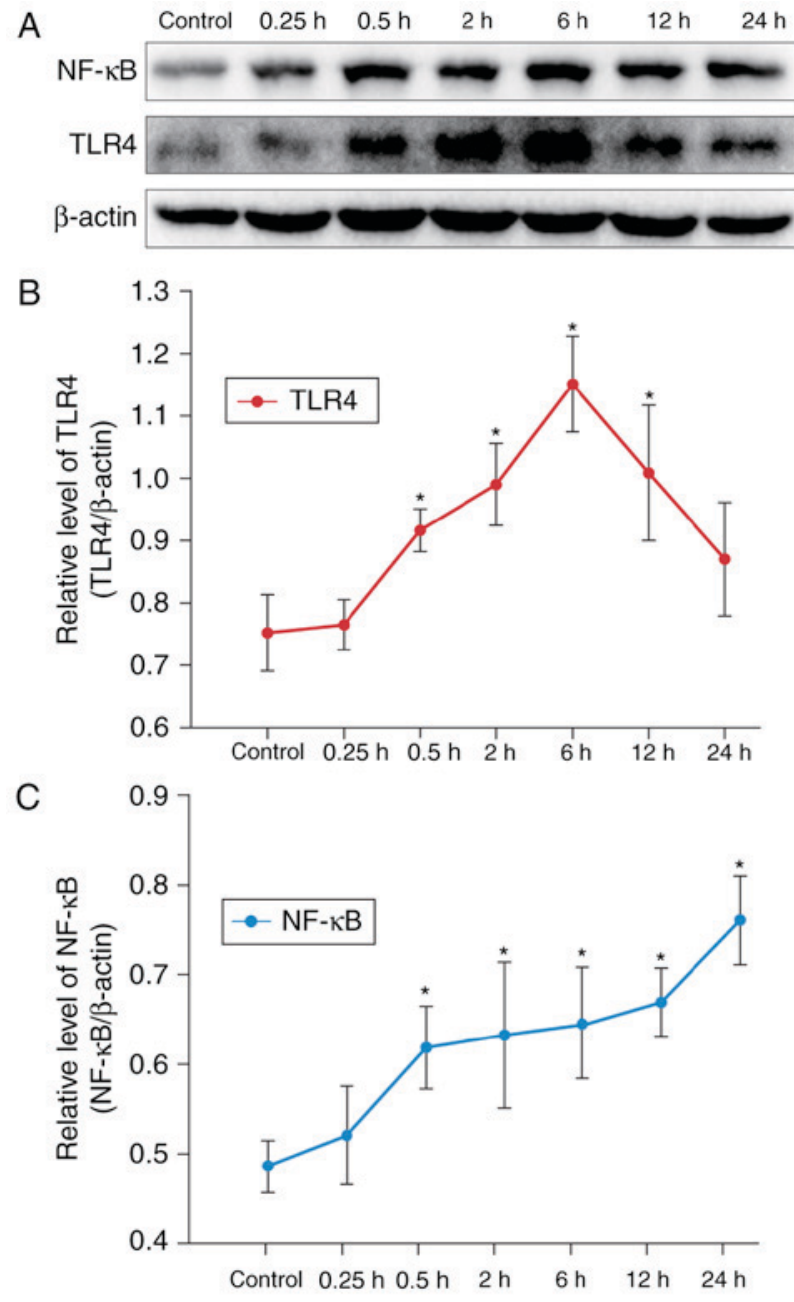

Figure 1. Dynamic alterations in TLR4 and NF- $\mathrm{B}$ expression levels within AR42J cells following CAE treatment. AR42J cells were treated in triplicate with vehicle or $10 \mathrm{nmol} / 1 \mathrm{CAE}$ for $0.25,0.5,2,6,12$ and $24 \mathrm{~h}$. (A) Western blotting was performed to analyze the relative protein expression levels of TLR4 and NF- $\kappa B$ within treated AR42J cells. Dynamics of (B) TLR4 and (C) NF- $\mathrm{KB}$ protein expression within AR42J cells treated with or without $10 \mathrm{nmol} / \mathrm{l} \mathrm{CAE}$ for the aforementioned durations. $\mathrm{P}<0.05$ vs. the control

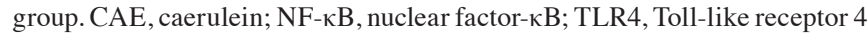

$0.5 \mathrm{~h}$ significantly increased the relative expression levels of TLR4 (Fig. 1B) and NF-kB (Fig. 1C) in AR42J cells (Fig. 1). The protein expression levels of TLR4 peaked after $6 \mathrm{~h}$ of CAE treatment, whereas CAE induced NF- $\mathrm{KB}$ expression in a time-dependent manner within AR42J cells. In our previous experiments, it was identified that the inflammatory response of AR42J cells was evident at $12 \mathrm{~h}$, and the expression of TLR4 and NF- $\mathrm{KB}$ increased markedly at this time point. Therefore, treatment with CAE for $12 \mathrm{~h}$ was selected as the model of CAE-induced acute inflammation for subsequent experiments.

To further determine the effects of CAE on TLR4 and $\mathrm{NF}-\kappa \mathrm{B}$, cells were treated with CAE or vehicle for $12 \mathrm{~h}$, after which TLR4 and NF- $\mathrm{KB}$ expression levels were determined by immunofluorescence. As presented in Fig. 2, weak anti-TLR4 fluorescence within the membranes and cytoplasm, and weak anti-NF- $\mathrm{kBp} 65$ fluorescence in the cytoplasm and nuclei was detected within the AR42J control cells. Conversely, increased anti-TLR4 and anti-NF-кBp65 fluorescence was observed within the CAE-treated cells; anti-NF- $\kappa B p 65$ fluorescence was greater within the nuclei of CAE-treated cells. Collectively, these results indicated that CAE induced TLR4 and NF- $\mathrm{KB}$ expression within AR42J cells.

Treatment with Ang 1-7 abrogates CAE-induced TLR4 and $N F-\kappa B$ expression within AR42J cells. Ang 1-7 has been reported to exhibit anti-inflammatory activities; the effects of Ang 1-7 on CAE-induced inflammation were investigated within AR42J cells that were treated with or without various concentrations of Ang 1-7 and were stimulated with CAE for $12 \mathrm{~h}$. Control cells were treated with vehicle alone. Relative protein expression levels of TLR4 and NF- $\kappa \mathrm{B}$ were determined via western blot analysis (Fig. 3). CAE treatment was observed to significantly enhance TLR4 and NF- $\kappa \mathrm{B}$ expression levels; however, pretreatment with Ang 1-7 (10-6 or $\left.10^{-7} \mathrm{~mol} / \mathrm{l}\right)$ failed to significantly modulate the effect of CAE on TLR4 and NF- $\mathrm{KB}$ expression. However, $10^{-5} \mathrm{~mol} / \mathrm{l}$ Ang 1-7 significantly abrogated CAE-induced TLR4 and NF- $\mathrm{BB}$ expression within AR42J cells.

Treatment with Ang 1-7 specific antagonist A779 enhances $C A E$-induced TLR4 and NF- $\kappa B$ expression within AR42J cells. Our previous study demonstrated that Ang 1-7 and its receptor Mas are expressed within AR42J cells (6). The effect of A779 on CAE-induced TLR4 and NF- $\mathrm{BB}$ expression was investigated in AR42J cells pretreated with various concentrations of A779 followed by CAE treatment for $12 \mathrm{~h}$. Relative expression levels of TLR4 and NF- $\mathrm{KB}$ were determined by western blot analysis. As presented in Fig. 4, treatment with A779 enhanced the expression levels of TLR4 and NF- $\mathrm{BB}$ within AR42J cells in a dose-dependent manner. Pretreatment with A779 $\left(10^{-5} \mathrm{~mol} / \mathrm{l}\right)$ significantly increased TLR4 and NF- $\mathrm{kB}$ expression compared with in the model group, in which cells were not pretreated with A779 for $12 \mathrm{~h}$. These results suggested that the reduction of CAE-induced expression of TLR4 and NF- $\mathrm{KB}$ was enhanced by A779 with AR42J cells.

Treatment with Ang 1-7 or A779 modulates CAE-induced cytokine expression within AR42J cells. The effects exerted by Ang 1-7 and A779 on CAE-induced cytokine expression were investigated. AR42J cells were pretreated with Ang 1-7 and were stimulated with CAE for $12 \mathrm{~h}$. The mRNA expression levels of IL-6, IL-8, TNF- $\alpha$ and IL-10 relative to GAPDH were detected using RT-qPCR. CAE treatment significantly enhanced IL-6, IL-8, TNF- $\alpha$ and IL-10 expression within AR42J cells $(\mathrm{P}<0.05$, Fig. 5A-D). Pretreatment with Ang 1-7 decreased IL-6, IL-8 and TNF- $\alpha$ expression in a dose-dependent manner. A significant decrease in IL-6 and TNF- $\alpha$ expression was observed with all concentrations of Ang 1-7, whereas IL-8 expression was decreased following treatment with $10^{-6}$ and $10^{-5} \mathrm{~mol} / 1$ Ang 1-7. Conversely, $10^{-6}$ and $10^{-5} \mathrm{~mol} / \mathrm{l}$ Ang 1-7 pretreatment increased IL-10 expression. Therefore, the addition of exogenous Ang 1-7 was associated with a reduction in the expression of proinflammatory cytokines and an increase in anti-inflammatory IL-10 expression within AR42J cells.

RT-qPCR was employed to investigate whether the effects of endogenous Ang 1-7 on CAE-induced cytokine expression may be antagonized by A779 within AR42J cells. Compared 


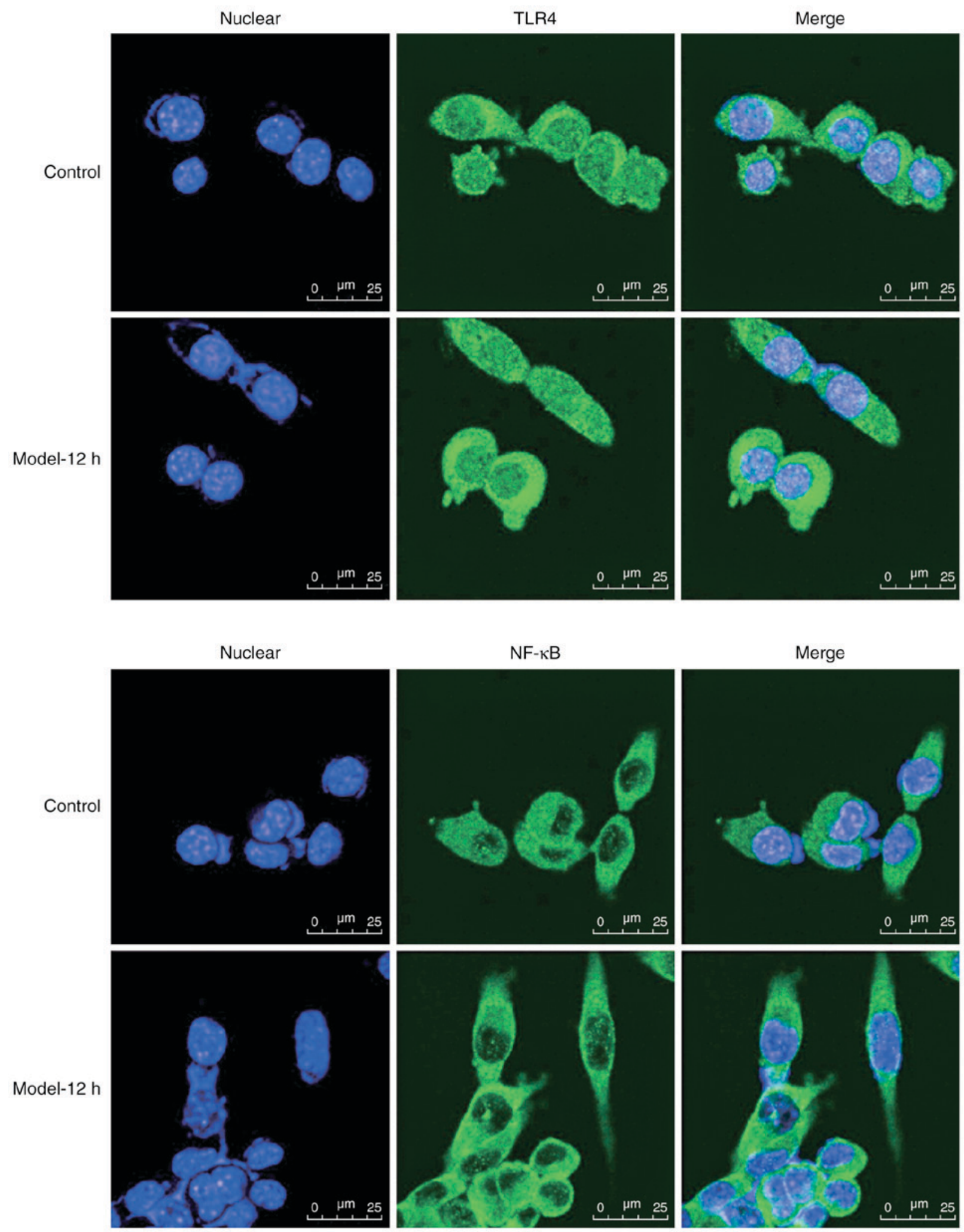

Figure 2. Immunofluorescence analysis of TLR4 and NF- $\mathrm{KB}$ expression within AR42J cells following CAE treatment. AR42J cells were treated in triplicate with vehicle or $10 \mathrm{nmol} / 1 \mathrm{CAE}$ for $12 \mathrm{~h}$; TLR4 and NF- $\mathrm{kB}$ expression levels were characterized by immunofluorescence analysis using FITC-anti-TLR4 and

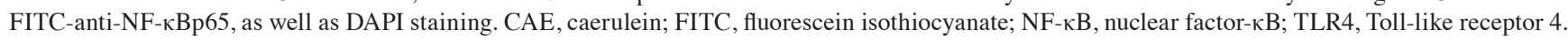

with the model group, pretreatment with $10^{-5} \mathrm{~mol} / \mathrm{l}$ A779 significantly increased CAE-induced expression of IL-6 and IL-8; CAE-induced expression of TNF- $\alpha$ expression within AR42J cells significantly increased with A779 pretreatment $\left(10^{-6}\right.$ and $10^{-5} \mathrm{~mol} / \mathrm{l} ; \mathrm{P}<0.05$, Fig. $\left.6 \mathrm{~A}-\mathrm{C}\right)$. Conversely, the
mRNA expression levels of IL-10 were decreased in response to A779 pretreatment, a significant decrease was observed with the addition of $10^{-6}$ and $10^{-5} \mathrm{~mol} / \mathrm{l} \mathrm{A} 779$, compared with in the control and model groups $(\mathrm{P}<0.05$; Fig. 6D). Collectively, antagonism of endogenous Ang 1-7 via A779 significantly 

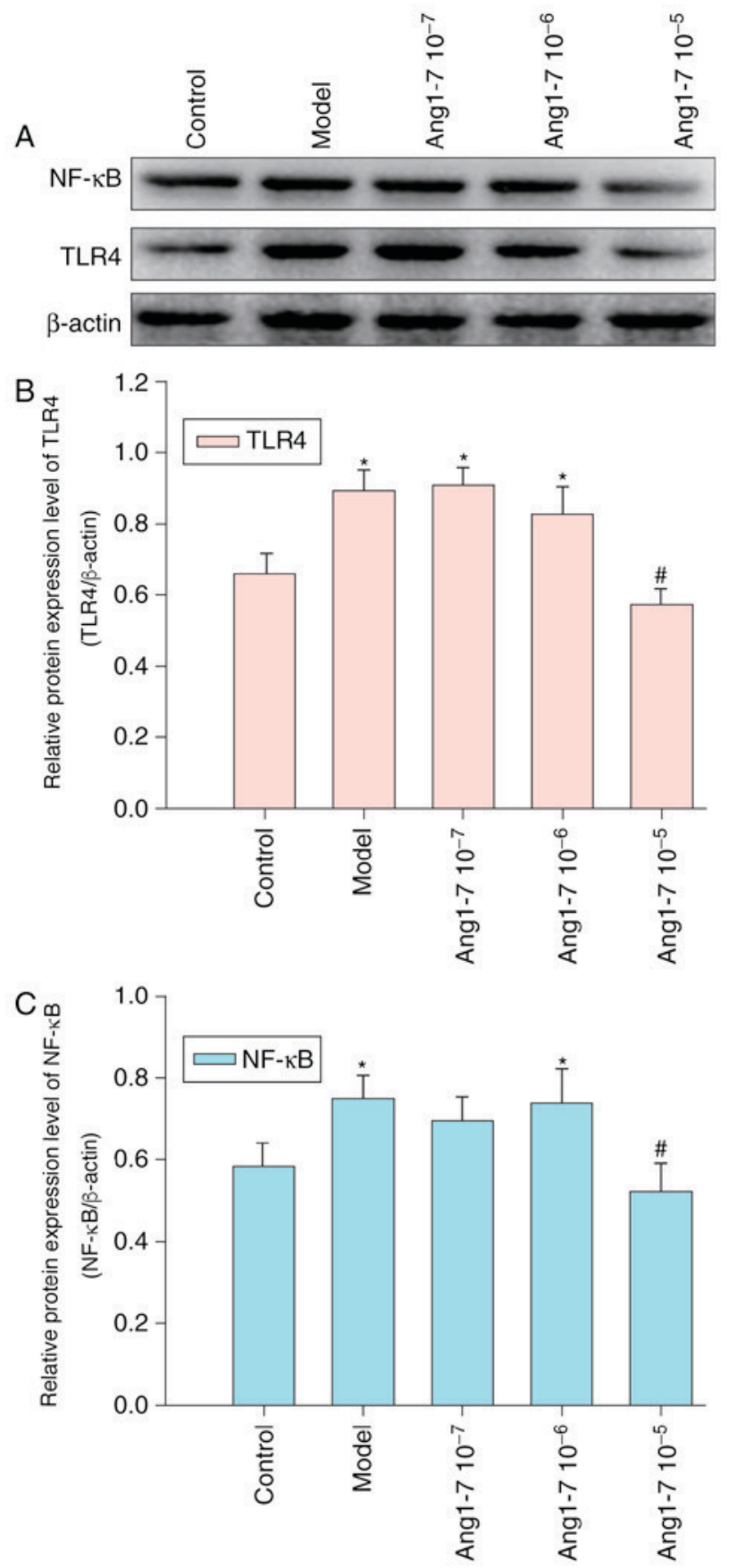

Figure 3. CAE-induced expression of TLR4 and NF-kB within AR42J cells is abrogated by Ang 1-7. (A) Western blotting revealed the protein expression levels of TLR4 and NF-kB within AR42J cells pretreated with or without Ang 1-7 $\left(10^{-7}, 10^{-6}\right.$ or $\left.10^{-5} \mathrm{~mol} / \mathrm{l}\right)$ for $12 \mathrm{~h}$ and stimulated with CAE for $12 \mathrm{~h}$; control cells received vehicle alone. Relative expression levels of (B) TLR4 and (C) NF- $\mathrm{kB}$ compared with $\beta$-actin. ${ }^{*} \mathrm{P}<0.05$ vs. the control group; ${ }^{\text {"}} \mathrm{P}<0.05$ vs. the model group. Ang, angiotensin; CAE, caerulein; NF- $\kappa \mathrm{B}$, nuclear factor- $\mathrm{kB}$; TLR4, Toll-like receptor 4.

enhanced CAE-induced expression of proinflammatory cytokines and decreased the expression of anti-inflammatory IL-10 within AR42J cells.

\section{Discussion}

Ang II and its receptors AT1 and AT2 serve important roles in the pathogenesis of AP, whereas Ang 1-7 has been reported to act
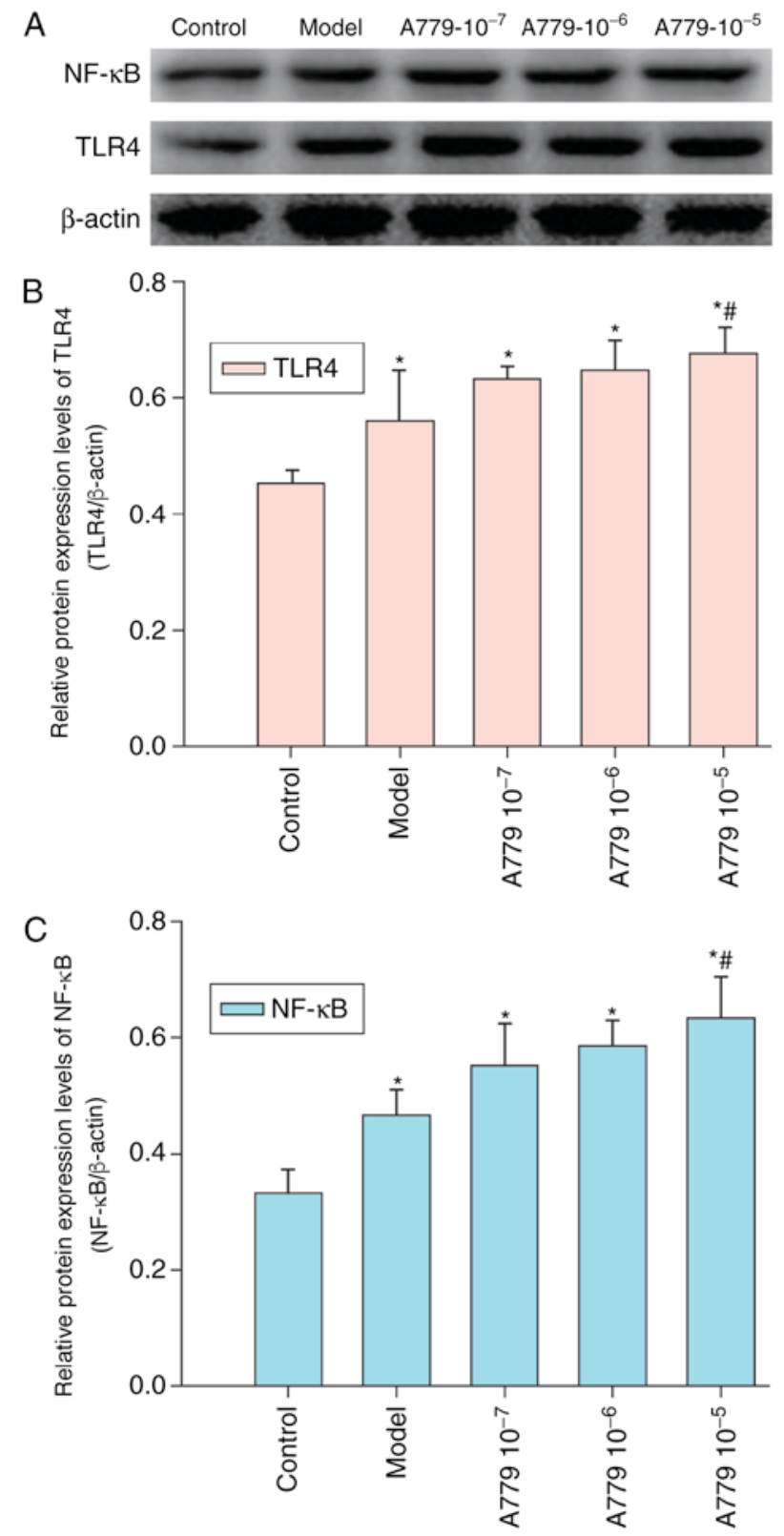

Figure 4. CAE-induced expression of TLR4 and NF- $\mathrm{kB}$ within AR42J cells is enhanced by A779. (A) Western blotting revealed the protein expression levels of TLR4 and NF- $\mathrm{KB}$ within AR42J cells pretreated with or without $10^{-7}, 10^{-6}$ or $10^{-5} \mathrm{~mol} / 1 \mathrm{~A} 779$ and CAE for $12 \mathrm{~h}$. Relative protein expression levels of (B) TLR4 and (C) NF- $\mathrm{kB}$ of the differentially treated AR42J cells, compared with $\beta$-actin. ${ }^{*} \mathrm{P}<0.05$ vs. the control group; ${ }^{\prime} \mathrm{P}<0.05$ vs. the model

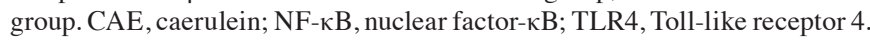

as an antagonist that inhibits inflammation (16,17). In addition, recent studies have demonstrated that Ang II can regulate TLR4 expression in order to modulate inflammation and other associated functions (18-20). In the present study, the effects of endogenous and exogenous Ang 1-7 on CAE-induced inflammation within AR42J cells were investigated. The purpose of the present study was to investigate the effect of Ang1-7 on TLR4/NF- $\mathrm{KB}$ and its possible anti-inflammatory mechanism by inhibiting TLR4 pathway, so the effect of ANG1-7 was blocked endogenously following the addition of the ANG1-7 antagonist A779. Endogenous blocking and exogenous increase of Ang1-7 was used to explore its role. The results revealed that CAE upregulated TLR4 and NF- $\mathrm{kB}$ expression; however, high 

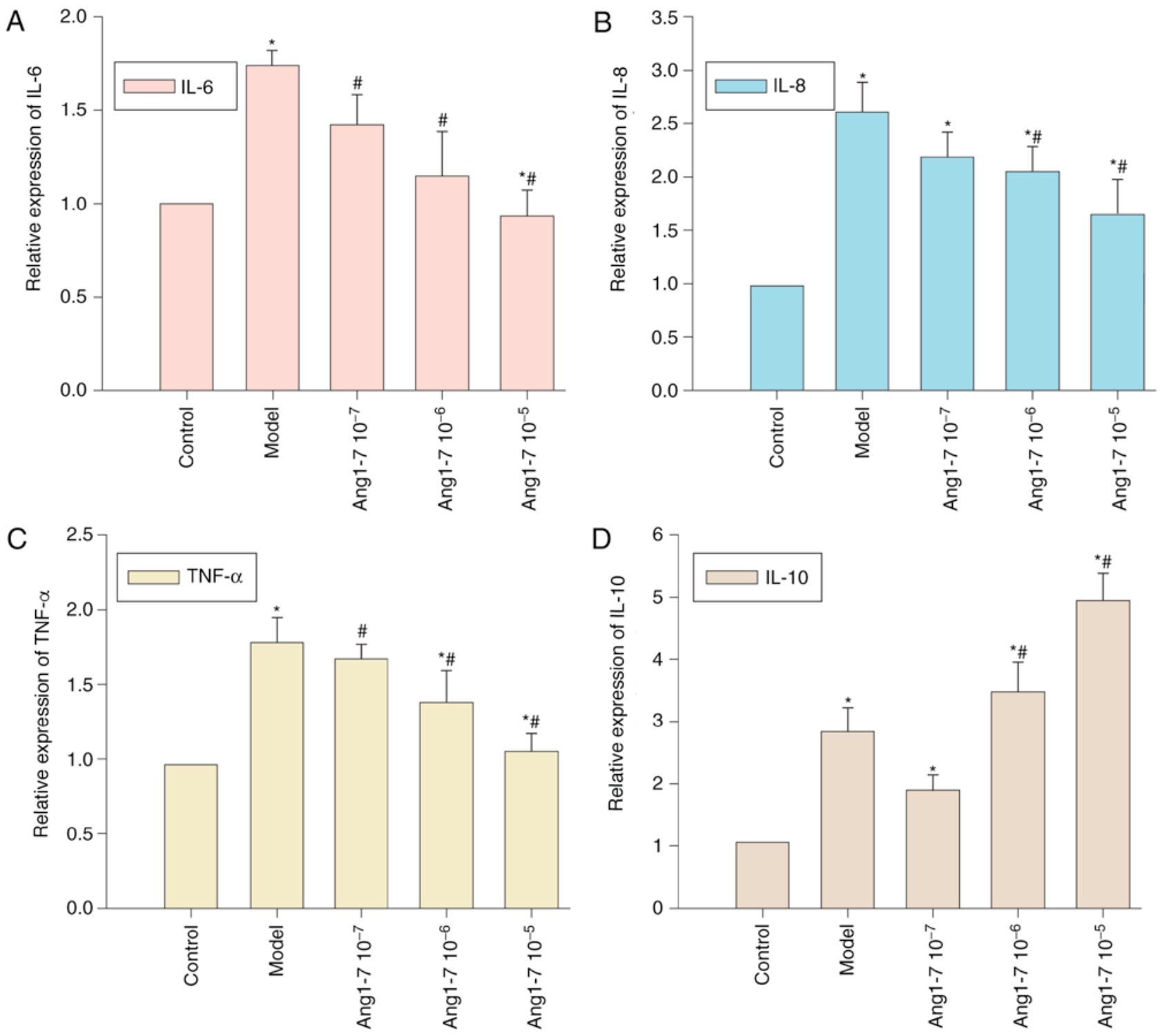

Figure 5. CAE-induced cytokine expression within AR42J cells is modulated by Ang 1-7. AR42J cells were pretreated with or without Ang 1-7 (10-7 $10^{-6}$ or $10^{-5} \mathrm{~mol} / \mathrm{l}$ ) for $12 \mathrm{~h}$ and CEA for $12 \mathrm{~h}$; control cells received vehicle alone. Relative mRNA expression levels of (A) IL-6, (B) IL-8, (C) TNF- $\alpha$ and (D) IL-10 in the differentially treated AR42J cells compared with GAPDH, as determined by reverse transcription-quantitative polymerase chain reaction. Relative mRNA expression levels of the cytokines within the control group are designated as $1 .{ }^{~} \mathrm{P}<0.05$ vs. the control group; ${ }^{*} \mathrm{P}<0.05$ vs. the model group. Ang, angiotensin; CAE, caerulein; IL, interleukin; TNF- $\alpha$, tumor necrosis factor- $\alpha$.

doses of Ang 1-7 abrogated CAE-induced TLR4 and NF- $\mathrm{B}$ expression in AR42J cells. Notably, Ang 1-7 is expressed within R42J cells following stimulation by CAE (6). The data of the present study indicated that endogenous Ang 1-7 may serve as a compensatory regulator to inhibit inflammation in an autocrine or paracrine manner during the inflammatory response in AP. This is supported by a previous report that Ang 1-7 inhibits the TLR4/NF- $\kappa \mathrm{B}$ signaling pathway and ameliorates inflammation of the liver (21); therefore, Ang 1-7 may be considered an anti-inflammatory factor that serves to downregulate the TLR4/NF- $\kappa \mathrm{B}$ signaling pathway during the pathogenic progression of AP. These novel findings suggested that Ang 1-7 may serve importance in the intervention of AP.

Pancreatitis has been recognized to be a result of the systemic inflammatory response which activate $N F-\kappa B$ and mitogen-activated protein kinases, which in turn regulate the expression of inflammatory cytokines, including IL-1 $\beta$, IL-6, interleukin- 8 and transforming growth factor- $\beta 1$ in caerulein-stimulated pancreatic acinar cells (22). Engagement of TLR 4 by its ligand can activate NF- $\kappa \mathrm{B}$ and other pathways to stimulate proinflammatory IL- 6 , IL- 8 and TNF- $\alpha$ production, which also upregulates anti-inflammatory IL-10 expression during the inflammatory process of AP (23-25). The findings of the present study demonstrated that CAE treatment significantly increased the relative expression levels of IL-6, IL-8, TNF- $\alpha$ and IL-10 within AR42J cells. A previous study demonstrated that pro-inflammatory cytokines, such as TNF- $\alpha$ and IL-6, were greatly increased, and the anti-inflammatory IL-10 was markedly decreased in the circulation after induction of SAP. The Ace $2 \mathrm{KO}$ mice exhibited increased levels of TNF- $\alpha$, IL-1 $\beta$, IL- 6 , multifocal coagulative necrosis and inflammatory infiltrate, and lower levels of serum IL-10 and pancreatic Ang-(1-7) compared with caerulein-treated WT 

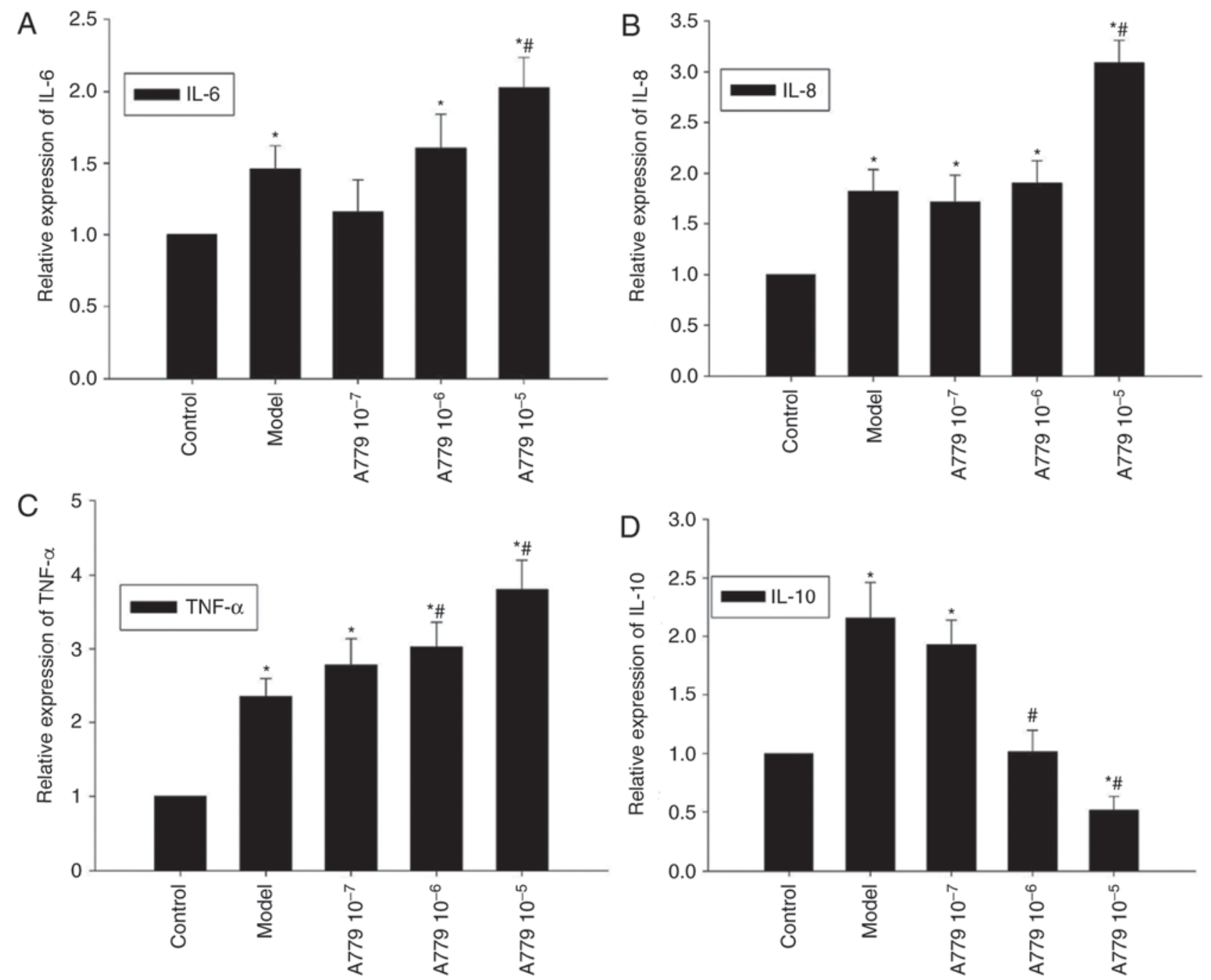

Figure 6. A779 affects CAE-induced cytokine production within AR42J cells. Following pretreatment with or without $10^{-7}, 10^{-6}$ or $10^{-5} \mathrm{~mol} / 1 \mathrm{~A} 779 \mathrm{for} 12 \mathrm{~h}$ and CAE for $12 \mathrm{~h}$, relative mRNA expression levels of (A) IL-6, (B) IL-8, (C) TNF- $\alpha$ and (D) IL-10 within AR42J cells were determined by reverse transcription-quantitative polymerase chain reaction, compared with GAPDH. Relative cytokine expression levels were designated as 1 (control group). ${ }^{*} \mathrm{P}<0.05$ vs. the control group; ${ }^{~} \mathrm{P}<0.05$ vs. the model group. CAE, caerulein; IL, interleukin; TNF- $\alpha$, tumor necrosis factor- $\alpha$.

mice at the same time point (1). Combined with the current research, these findings suggested that an imbalance between proinflammatory and anti-inflammatory cytokine responses is crucial for the pathogenesis of AP. In addition, treatment with exogenous Ang 1-7 reduced the CAE-induced IL-6, IL-8 and TNF- $\alpha$ expression, but increased IL-10 production in AR42J cells. Conversely, antagonism of Ang 1-7 exerted by A779 treatment increased CAE-induced expression of IL-6, IL-8 and TNF- $\alpha$, and decreased IL-10 expression within AR42J cells. Additionally, endogenous and exogenous Ang 1-7 has been reported to modulate the imbalance between pro- and anti-inflammatory cytokine responses to limit inflammation during the pathogenesis of AP (26). A previous study suggested that inflammatory cytokines may be considered prognostic markers in the progression of SAP (27). The findings of the present study indicated that the imbalance between pro- and anti-inflammatory cytokine responses may serve importance in the evaluation of AP-associated inflammation reaction. Whether endogenous and exogenous Ang 1-7 can downregulate TLR4 and NF- $\mathrm{KB}$ expression, and alter the imbalance between pro- and anti-inflammatory cytokines, in vivo remains to be elucidated. In addition, the potential mechanisms underlying the effects of Ang 1-7 on TLR-4 and NF- $\kappa B$ expression during the progression of AP have yet to be investigated.

In conclusion, the results of the present study indicated that CAE induced the expression of TLR4 and NF- $\kappa B$, as well as pro- and anti-inflammatory cytokines, within AR42J cells, which was downregulated by endogenous and exogenous Ang 1-7. These findings may provide novel insights into the pathophysiological mechanism of pancreatitis and provide a new target for the treatment of pancreatitis.

\section{Acknowledgements}

The authors of the present study would like to thank their colleagues and the expert panel members for their support and help. The present study was supported by grants from the National Natural Science Foundation of China (grant no. 81441060), the Research Foundation of Beijing Friendship Hospital, Capital Medical University (grant no. yyqdkt2014-4) and Beijing Municipal Administration of Hospitals' Youth Programme, (grant no. QML20150104). 


\section{References}

1. Liu R, Qi H, Wang J, Wang Y, Cui L, Wen Y and Yin C: Angiotensin-converting enzyme (ACE and ACE2) imbalance correlates with the severity of cerulein-induced acute pancreatitis in mice. Exp Physiol 99: 651-663, 2014.

2. Wang Y, Wang J, Liu R, Qi H, Wen Y, Sun F and Yin C: Severe acute pancreatitis is associated with upregulation of the ACE2-angiotensin-(1-7)-Mas axis and promotes increased circulating angiotensin-(1-7). Pancreatology 12: 451-457, 2012.

3. Mori J, Patel VB, Ramprasath T, Alrob OA, DesAulniers J, Scholey JW, Lopaschuk GD and Oudit GY: Angiotensin 1-7 mediates renoprotection against diabetic nephropathy by reducing oxidative stress, inflammation, and lipotoxicity. Am J Physiol Renal Physiol 306: F812-F821, 2014.

4. Lu CL, Wang Y, Yuan L, Li Y and Li XY: The angiotensinconverting enzyme 2/angiotensin (1-7)/Mas axis protects the function of pancreatic $\beta$ cells by improving the function of islet microvascular endothelial cells. Int J Mol Med 34: 1293-300, 2014.

5. Yuan L, Lu CL, Wang Y, Li Y and Li XY: Ang (1-7) protects islet endothelial cells from palmitate-induced apoptosis by AKT, eNOS, p38 MAPK, and JNK pathways. J Diabetes Res 2014: 391476, 2014.

6. Wang J, Liu R, Qi H, Wang Y, Cui L, Wen Y, Li H and Yin C: The ACE2-angiotensin-(1-7)-Mas axis protects against pancreatic cell damage in cell culture. Pancreas 44: 266-272, 2015

7. Gordon S: Pattern recognition receptors: Doubling up for the innate immune response. Cell 111: 927-930, 2002.

8. Pan LF, Yu L, Wang LM, He JT, Sun JL, Wang XB, Bai ZH, Wang H, Yan TL and Pei HH: The Toll-like receptor 4 antagonist TAK-242 protects against chronic pancreatitis in rats. Mol Med Rep 16: 3863-3868, 2017.

9. Li G, Wu X, Yang L, He Y, Liu Y, Jin X and Yuan H: [Corrigendum] TLR4-mediated NF- $\mathrm{kB}$ signaling pathway mediates HMGB1-induced pancreatic injury in mice with severe acute pancreatitis. Int J Mol Med 38: 1313, 2016.

10. Awla D, Abdulla A, Regnér S and Thorlacius H: TLR4 but not TLR2 regulates inflammation and tissue damage in acute pancreatitis induced by retrograde infusion of taurocholate. Inflamm Res 60: 1093-1098, 2011.

11. Xue $J$ and Habtezion A: Carbon monoxide-based therapy ameliorates acute pancreatitis via TLR4 inhibition. J Clin Invest 124: 437-447, 2014.

12. Li S, Lu H, Hu X, Chen W, Xu Y and Wang J: Expression of TLR4-MyD88 and NF- $\mathrm{BB}$ in the iris during endotoxin-induced uveitis. Mediators Inflamm 2010: 748218, 2010.

13. Chan YC and Leung PS: Angiotensin II type 1 receptor-dependent nuclear factor-kappaB activation-mediated proinflammatory actions in a rat model of obstructive acute pancreatitis. J Pharmacol Exp Ther 323: 10-18, 2007

14. Yu JH, Lim JW and Kim H: Altered gene expression in cerulein-stimulated pancreatic acinar cells: Pathologic mechanism of acute pancreatitis. Korean J Physiol Pharmacol 13: 409-416, 2009.
15. Livak KJ and Schmittgen TD: Analysis of relative gene expression data using real-time quantitative PCR and the 2(-Delta Delta C(T)) method. Methods 25: 402-408, 2001.

16. Furukawa H, Shinmura A, Tajima H, Tsukada T, Nakanuma $\mathrm{S}$, Okamoto K, Sakai S, Makino I, Nakamura K, Hayashi H, et al: Concentration of tissue angiotensin II increases with severity of experimental pancreatitis. Mol Med Rep 8: 335-338, 2013.

17. Shimizu K: Mechanisms of pancreatic fibrosis and applications to the treatment of chronic pancreatitis. J Gastroenterol 43: 823-832, 2008

18. Dange RB, Agarwal D, Masson GS, Vila J, Wilson B, Nair A and Francis J: Central blockade of TLR4 improves cardiac function and attenuates myocardial inflammation in angiotensin II-induced hypertension. Cardiovasc Res 103: 17-27, 2014.

19. Lv J, Chen Q, Shao Y, Chen Y and Shi J: Cross-talk between angiotensin-II and toll-like receptor 4 triggers a synergetic inflammatory response in rat mesangial cells under high glucose conditions. Biochem Biophys Res Commun 459: 264-269, 2015.

20. Wolf G, Bohlender J, Bondeva T, Roger T, Thaiss F and Wenzel UO: Angiotensin II upregulates toll-like receptor 4 on mesangial cells. J Am Soc Nephrol 17: 1585-1593, 2006.

21. Santos SH, Andrade JM, Fernandes LR, Sinisterra RD, Sousa FB, Feltenberger JD, Alvarez-Leite JI and Santos RA. Oral Angiotensin-(1-7) prevented obesity and hepatic inflammation by inhibition of resistin/TLR4/MAPK/NF- $\mathrm{B} B$ in rats fed with high-fat diet. Peptides 46: 47-52, 2013.

22. Ju KD, Lim JW, Kim KH and Kim H: Potential role of NADPH oxidase-mediated activation of Jak2/Stat 3 and mitogen-activated protein kinases and expression of TGF- $\beta 1$ in the pathophysiology of acute pancreatitis. Inflamm Res 60: 791-800, 2011.

23. Johnson GB, Brunn GJ and Platt JL: Cutting edge: An endogenous pathway to systemic inflammatory response syndrome (SIRS)-like reactions through Toll-like receptor 4. J Immunol 172: 20-24, 2004.

24. Lai JL, Liu YH, Liu C, Qi MP, Liu RN, Zhu XF, Zhou QG, Chen YY, Guo AZ and Hu CM: Indirubin inhibits LPS-induced inflammation via TLR4 abrogation mediated by the NF- $\kappa B$ and MAPK signaling pathways. Inflammation 40: 1-12, 2017.

25. Xu M, Wang KN, Wu $\mathrm{K}$ and Wang XP: Pyrrolidine dithiocarbamate inhibits nuclear factor $\kappa \mathrm{B}$ and Toll-like receptor 4 expression in rats with acute necrotizing pancreatitis. Gut Liver 9: 411-416, 2015.

26. Simões e Silva AC, Silveira KD, Ferreira AJ and Teixeira MM ACE2, angiotensin-(1-7) and Mas receptor axis in inflammation and fibrosis. Br J Pharmacol 169: 477-492, 2013.

27. Aoun E, Chen J, Reighard D, Gleeson FC, Whitcomb DC and Papachristou GI: Diagnostic accuracy of interleukin-6 and interleukin- 8 in predicting severe acute pancreatitis: A meta-analysis. Pancreatology 9: 777-785, 2009.

This work is licensed under a Creative Commons Attribution-NonCommercial-NoDerivatives 4.0 International (CC BY-NC-ND 4.0) License. 